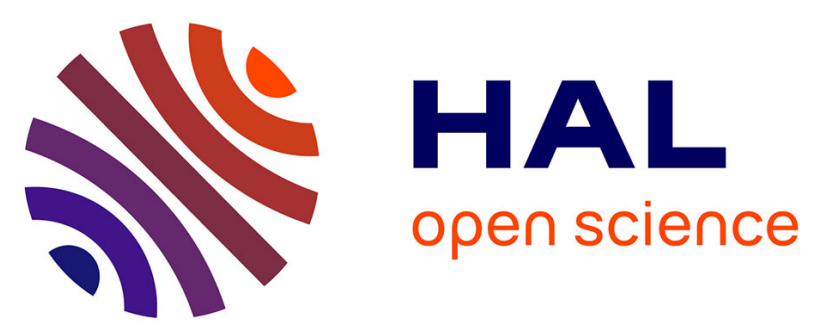

\title{
THE ECONOMIC CONSEQUENCES OF NON-ADHERENCE TO LIPID-LOWERING THERAPY - RESULTS FROM THE ANGLO-SCANDINAVIAN-CARDIAC OUTCOMES TRIAL (ASCOT)
}

Peter Lindgren, Jennifer Eriksson, Martin Buxton, Thomas Kahan, Neil Poulter, Bjorn Dahlof, Peter Sever, Hans Wedel, Bengt Jönsson

\section{- To cite this version:}

Peter Lindgren, Jennifer Eriksson, Martin Buxton, Thomas Kahan, Neil Poulter, et al.. THE ECONOMIC CONSEQUENCES OF NON-ADHERENCE TO LIPID-LOWERING THERAPY - RESULTS FROM THE ANGLO-SCANDINAVIAN-CARDIAC OUTCOMES TRIAL (ASCOT). International Journal of Clinical Practice, 2010, 64 (9), pp.1228. 10.1111/j.1742-1241.2010.02445.x . hal00552665

\section{HAL Id: hal-00552665 https://hal.science/hal-00552665}

Submitted on 6 Jan 2011

HAL is a multi-disciplinary open access archive for the deposit and dissemination of scientific research documents, whether they are published or not. The documents may come from teaching and research institutions in France or abroad, or from public or private research centers.
L'archive ouverte pluridisciplinaire HAL, est destinée au dépôt et à la diffusion de documents scientifiques de niveau recherche, publiés ou non, émanant des établissements d'enseignement et de recherche français ou étrangers, des laboratoires publics ou privés. 


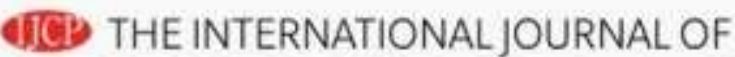 CLINICAL PRACTICE}

\section{THE ECONOMIC CONSEQUENCES OF NON-ADHERENCE TO LIPID-LOWERING THERAPY - RESULTS FROM THE ANGLO- SCANDINAVIAN-CARDIAC OUTCOMES TRIAL (ASCOT)}

\begin{tabular}{|r|l|}
\hline Journal: & International Journal of Clinical Practice \\
\hline Manuscript ID: & IJCP-12-09-0751.FT10.R1 \\
\hline Wiley - Manuscript type: & Original Paper \\
\hline Date Submitted by the & 08-Feb-2010 \\
\hline Complete List of Authors: & $\begin{array}{l}\text { Lindgren, Peter; i3 Innovus; Karolinska Institutet, Institute of } \\
\text { Environmental Medicine } \\
\text { Eriksson, Jennifer; i3 Innovus } \\
\text { Buxton, Martin; Brunel Univeristy } \\
\text { Kahan, Thomas; Karolinska Institutet, Department of Clinical } \\
\text { Sciences, Danderyd Hospital } \\
\text { Poulter, Neil; Imperial College } \\
\text { Dahlof, Bjorn; Sahlgrenska University Hospital, Institute of Medicine } \\
\text { Sever, Peter; Imperial College } \\
\text { Wedel, Hans; Nordic School of Public Health } \\
\text { Jönsson, Bengt; Stockholm School of Economics, Dept of Economics }\end{array}$ \\
\hline Specialty area: & \begin{tabular}{l} 
\\
\hline
\end{tabular} \\
\hline
\end{tabular}

\section{s scholarONE" \\ Manuscript Central}


THE ECONOMIC CONSEQUENCES OF NON-ADHERENCE TO LIPID-

\title{
LOWERING THERAPY - RESULTS FROM THE ANGLO-SCANDINAVIAN-
}

\section{CARDIAC OUTCOMES TRIAL (ASCOT)}

Peter Lindgren ${ }^{1,2}$, Jennifer Eriksson ${ }^{1}$, Martin Buxton ${ }^{3}$, Thomas Kahan ${ }^{4}$, Neil R Poulter ${ }^{5}$, Björn Dahlöf ${ }^{6}$, Peter S Sever ${ }^{5}$, Hans Wedel ${ }^{7}$, Bengt Jönsson ${ }^{8}$ on behalf of the ASCOT trial investigators

\author{
${ }^{1}$ i3 Innovus, Stockholm, Sweden \\ ${ }^{2}$ Division of cardiovascular epidemiology, Institute of Environmental Medicine, \\ Karolinska Institutet, Stockholm, Sweden \\ ${ }^{3}$ Brunel University, Uxbridge, UK \\ ${ }^{4}$ Department of Clinical Sciences, Danderyd Hospital, Karolinska Institutet, Stockholm, \\ Sweden \\ ${ }^{5}$ Imperial College, London, UK \\ ${ }^{6}$ Sahlgrenska University Hospital/Östra, Göteborg, Sweden \\ ${ }^{7}$ Nordic School of Public Health, Göteborg, Sweden \\ ${ }^{8}$ Centre for Health Economics, Stockholm School of Economics, Stockholm, Sweden
}

Running title: The economics of adherence in ASCOT 
Disclosures: PL, MB, TK, NP, BD, PS, HW and BJ have served as consultants to and received travel expenses, payment for speaking at meetings or funding for research from pharmaceutical companies marketing anti-hypertensive drugs, including AstraZeneca, Boehringer-Ingelheim, Bristol-Myers Squibb Co, Merck, Sharpe and Dohme, Novartis, Pfizer, Sanofi-Aventis and Servier.. PL, MB, TK, NP, BD, PS, HW and BJ received financial support from Pfizer to cover administrative and staffing costs of ASCOT, as well as travel and accommodation expenses incurred by attending relevant meetings.

\author{
Address for correspondence: \\ Peter Lindgren \\ i3 Innovus \\ Klarabergsviadukten 90D \\ 11164 Stockholm \\ Sweden \\ Peter.lindgren@i3innovus.com \\ Fax: + 48854528542
}

Word count: 3037 (max 3800 including tables and figures)

Tables: 3 (counts as 250 words each) 
projected survival and quality-adjusted survival (QALY) would also be longer (10.83 compared to 10.81 life years and 8.13 compared to 8.11 QALYs).

\section{Conclusion}

Given the higher risk of cardiovascular events associated with low adherence shown here, measures to improve adherence are an important part of the prevention of cardiovascular disease.

Key-words (3 -10): Hydroxymethylglutaryl-CoA reductase inhibitors, atorvastatin, medication adherence, primary prevention, economics, hypertension

\section{What's known?}

- Adherence to statin therapy in clinical practice is less than ideal.

- Registry studies indicate an association between low adherence to statin therapy and cardiovascular outcomes.

\section{What's new?}

- There is a significant reduction of events in patients in primary prevention who are adherent.

- This reduction is predicted to lead to health gains and somewhat lower costs of hospitalizations. 


\section{Introduction}

The clinical benefits of statin therapy have been extensively demonstrated in a range of clinical trials and best evidence suggests that a "lower the better" policy is probably best | clinical practice, at least in secondary prevention. [1-6] Consequently, proper control of cholesterol is an important therapeutic goal in both primary and secondary prevention of cardiovascular disease. [7] In spite of this, several studies indicate that adherence to lipid lowering therapy is less than ideal, with estimates of the proportion of patients remaining on treatment after 1 year ranging between $25 \%$ and $90 \%$, with a downward trend over time. [8-13]

Poor adherence to therapy have important clinical consequences: Registry data have shown an association between all-cause mortality and low adherence to statin therapy. [14] A similar pattern has been observed for the use of cardioprotective medications in diabetic patients. [15] In primary prevention, studies have indicated increased risk of coronary heart disease (CHD) and congestive heart failure (CHF) in patients with poor adherence. $[16,17]$ In economic terms, poor adherence could lead to lower cost of drug if patients do not fill their prescriptions, but also higher costs associated with a higher risk of cardiovascular events. In a retrospective population based registry study conducted in the US, Sokol and colleagues investigated the association between adherence to statin therapy among 2,981 patients stratified into five groups defined by medical possession ratio. The investigators found a statistical significant reduction in total health care costs (defined as drug costs and cost of hospitalizations for any cause) with increased adherence. [18] To our knowledge, this is the only study considering the economic 
aspects of poor adherence to statin therapy based on observational data as opposed to assumptions regarding the effect of poor adherence.

The Anglo-Scandinavian Cardiac Outcomes Trial (ASCOT) was a multicentre randomised trial in which two antihypertensive treatment strategies for the reduction of CHD was investigated in 19,257 patients with no prior or current history of CHD. In the blood pressure-lowering arm of ASCOT (ASCOT-BPLA) a newer regimen of antihypertensive drugs based on the calcium channel blocker amlodipine, adding the angiotensin-converting enzyme inhibitor perindopril as required to reach blood pressure targets (amlodipine-based), was compared with an older regimen based on the betablocker atenolol, adding the diuretic bendroflumethiazide with potassium as required (atenolol-based). In addition, in a $2 \times 2$ factorial design, the trial included a double-blind lipid-lowering arm (ASCOT-LLA) - a comparison of atorvastatin to placebo in 10,305 patients. This part of the trial was closed early (after a median follow-up of 3.3 years) after a recommendation by the data safety monitoring board on the grounds that atorvastatin had resulted in a highly significant reduction in the primary endpoint (nonfatal myocardial infarction, MI, and fatal CHD) as well as a reduction in the number of strokes. [1] The blood-pressure lowering arm was also stopped prematurely on the ground of higher efficacy of the amlodipine-based therapy after a median follow-up of 5.5 years. [19] After the early termination of the lipid-lowering arm, the choice to remain on drug or discontinue was left at the discretion of the treating physician and patient. Data were however continuously collected as part of the ongoing blood-pressure lowering arm. At the end of follow-up, patients originally randomized to atorvastatin had 
1

2

3

4

5

6

7

8

9

10

11

12

13

14

15

16

17

18

19

20

21

22

23

24

25

26

27

28

29

30

31

32

33

34

35

36

37

38

39

40

41

42

43

44

45

46

47

48

49

50

51

52

53

54

55

56

57

58

59

60

a $36 \%$ lower risk of the primary end-point in spite of crossing between treatments, potentially due to carry-over benefits. [20]

The objectives of our study were two-fold: First to study the association between adherence and cardiovascular outcomes during the follow-up after the closure of the lipid lowering arm, and second to quantify the long-term economic consequences and health outcomes linked to reduced adherence.

\section{Methods \\ Patients}

The design and inclusion criteria of ASCOT-LLA have been described in detail previously. [21] The trial included men and women aged between 40 and 79 years, with either untreated hypertension (systolic blood pressure $>160 \mathrm{~mm} \mathrm{Hg}$ and/or diastolic blood pressure $>100 \mathrm{~mm} \mathrm{Hg}$ ) or treated hypertension with systolic blood pressure $>140 \mathrm{~mm} \mathrm{Hg}$ and/or diastolic blood pressure $>90 \mathrm{~mm} \mathrm{Hg}$ and who, while not being treated with a statin or fibrate, had a total cholesterol concentration of $6.5 \mathrm{mmol} / \mathrm{L}$ or less. Patients were also required to have at least three of the following risk factors: male sex, age 55 years or older, microalbuminuria or proteinuria, current smoker, a ratio of plasma total cholesterol to HDL-cholesterol of 6 or higher, a family history of early CHD, left ventricular hypertrophy, other specified abnormalities on electrocardiogram, type 2 diabetes, peripheral arterial disease, previous stroke or transient ischaemic attack. 
In order to assess the impact of low adherence on total cardiovascular events and procedures (including fatal CHD, silent and non-silent MI, fatal and non-fatal stroke, fatal and non-fatal heart failure, stable and unstable angina, peripheral artery disease, lifethreatening arrhythmias and revascularisation procedures such as coronary artery by-pass grafting, $\mathrm{CABG}$, and percutaneous coronary interventions, $\mathrm{PCI}$ ), patients randomized to atorvastatin without events before the closure of the lipid-lowering arm were included in this analysis.

The impact of low adherence on cardiovascular events

The number of days on drug (start and stop dates) were collected as part of the case report forms of the trial. Based on this information, adherence was defined as the proportion of days covered (PDC), with high adherence defined as PDC $>80 \%$ and low adherence as $\mathrm{PDC}<50 \%$.

$\mid$ To control for underlying cardiovascular risk, we created a risk score by fitting a logistic Deleted: each patient was assigned a risk score based on their risk factor profile. regression model to the patient level data in the placebo arm of the trial, and included male sex, older age ( $>60$ years), current smoker, systolic and diastolic blood pressure, total cholesterol, LDL cholesterol and HDL cholesterol, history of cerebrovascular disease, diabetes, left ventricular hypertrophy and blood pressure regimen. This was then used to assign a risk score to each patient in our study sample based on their risk factor profile. 
Two statistical models were used to assess the impact of adherence on cardiovascular events: A Cox proportional hazards model and a Poisson regression model. Both models included cardiovascular risk (based on the risk score described above), accumulated adherence and current age of the patients. The Poisson model also included time since the Deleted: (three groups based on PDC, entry in the follow-up. We were primarily interested in investigating high adherence compared to low, but in order not to loose patients, accumulated adherence (based on PDC) was divided into three groups (less than $50 \%$, between 50 and $80 \%$ and above $80 \%$ ) with the lowest groups used as the reference group in the regressions.

The impact of low adherence on health economic endpoints

To assess the long-term impact of poor adherence we used a Markov model based on the ASCOT patient-level data. This model has been described in detail elsewhere. [22] Briefly, the model consists of five health states describing the health of the patient: Event free, MI, revascularization, stroke and death. Only the first MI, revascularization and stroke are explicitly included in the model although costs from subsequent events were included when attributing cost to each health state. Each year, the risk of moving between the health states is governed by transition probabilities derived using survival analysis from the trial data, taking age, gender, blood pressure lowering regime and the use of atorvastatin into account. Survival following events was assumed to be the same irrespective of current treatment.

Costs in the model (expressed in $2007 £$ ) were based on the resource consumption following an event in the trial. For atorvastatin, we used the listed price of $0.64 £$ per day 
with the total cost in the two arms depending on the actual observed adherence. Each health state is also associated with utility weights to predict the number of quality adjusted life years (QALY) associated with the different treatments. Utility weights for the health states were based on a previously published substudy of ASCOT patients using the EQ-5D to assess the health following events, converting responses to utility weights using social valuations from the UK. [23]

To assess the impact of adherence, we used the model to compare a group of patients with high adherence (PDC $>80 \%$ ) during the open-label follow-up to a groups of patients with low adherence (PDC $<50 \%$ ) by adjusting the risks with the relative risk observed in the Poisson model described above. We assumed that patients would receive an amlodipine-based antihypertensive therapy and therefore have the underlying risk as patients with amlodipine in combination with atorvastatin, as this has previously been indicated to be cost-effective in comparison to an atenolol-based strategy. [24] At the end of follow-up, patients in both arms of the model were assumed to have the same risk as those of amlodipine-treated patients alone, and the model is run until all patients are dead.

To assess the impact of parameter uncertainty on the results, a probabilistic sensitivity analysis (PSA) as undertaken where each model input parameter was drawn from its underlying distribution. For transition probabilities, costs and utility weights, the empirical distributions were used (estimated by bootstrapping from the original patient level data). The relative risk associated with high adherence was assumed to be lognormal and the proportion of patients on drug in the high and low adherence arms were 
assumed to be beta-distributed. One-way sensitivity analysis of key model inputs was

also conducted.

The analyses were performed from the perspective of the UK NHS, with costs and outcomes discounted at a rate of $3.5 \%$ per annum in accordance with the recommendations made by NICE. [25]

\section{Results}

In total, 4671 patients were included in the study with a median of 2.4 years of follow-up. Table 1 shows the demographic characteristics at baseline for patients with high and low adherence (548 patients fell into the middle group, data not shown for these). The groups are fairly similar in their characteristics, with no marked pattern of higher risk patients in one group or the other.

$<$ Table 1>

As can be seen in table 2, patients with high adherence have a significantly lower risk of cardiovascular events than patients with low adherence. There is also a numerically lower risk for the limited number of patients with medium adherence (PDC $50-80 \%$ ), although this was not statistically significant. The Cox proportional hazards model and Poisson regression model show very similar results.

$<$ Table $2>$ 
The Markov model predicts that 1 first event per 100 treated patients is avoided by high adherence. $43 \%$ of the events would be $\mathrm{MI}$ or fatal $\mathrm{CHD}, 29 \%$ revascularixation

procedures and $28 \%$ stroke. In table 3 , the projected long-term effects of low adherence predicted by the model are presented. $10 \%$ of the treatment cost in the high adherence

Deleted: Markov group is offset by savings due to fewer events.

<Table 3>

Figure 1 shows the results from the PSA based on 1,000 replications in the form of a

Formatted: Font: Not Bold cost-effectiveness scatter plot. In the vast majority of the simulations, high adherence is associated with positive long term outcomes.

4

$\leq$ Figure $1>$

Formatted: Font: Not Bold

Formatted: Font: Not Bold

Figure 2 shows a tornado diagram of the results from the one-way sensitivity analyses.

Formatted: Font: Not Bold

Formatted: Font: Not Bold

$\underline{\text { Results are most sensitive to the relative risk associated with high adherence. Results are }}$

also sensitive to assumptions on the cost of drug in the low adherence arm. The upper

bound in the analysis represent a situation where costs are only incurred for days where

the drug was consumed (on average $7 \%$ of days), while the upper bound would indicate a

$\underline{\text { situation where drug costs are incurred for the entire period, representing wastage of drug }}$

for all days where it is not consumed. A situation between these extremes would

represent a situation where some, but not all, of the prescriptions are filled by the patient. 
Changes to the start age of the patient (which could be seen as a proxy for risk), the

discount rate applied, and changes to utility decrement caused by and costs associated

with events has relatively mall impact.

Based on the findings in a meta-analysis of clinical trial data where patients with good adherence to placebo had better survival than those with poor adherence, a healthy adherer effect has been proposed. [27] This would imply that patients with generally good health would be more likely to take the drug, and therefore introduce a bias when measuring the effect of adherence. In our analysis, we control for underlying cardiovascular risk, and so a healthy adherer effect is unlikely to explain our findings. 
The use of $80 \%$ of days covered as a cut-off for cost-effectiveness is of course arbitrary, and does not constitute a magic boundary. It is however consistent with much of the published literature on adherence. [28]

When extrapolating over a longer timeframe, our model predicts that $10 \%$ of the cost of drug is saved through reduction in other health care costs in patients with high adherence. The avoided events are also predicted to lead to an improved quality-adjusted survival of 0.02 QALYs. Compared to the findings of Sokol and colleagues where a reduction of total costs was observed our results may seem small [18] One explanatory factor is that

Deleted: This may seem small c Deleted: for instance Deleted: for instance Deleted: the cost associated with e.g. hospitalizations in the US is generally considerably higher compared to the UK, which leads to higher savings from each avoided event. The main reason however, can be found in the underlying absolute risk of cardiovascular disease: The ASCOT-LLA population is a primary prevention population treated intensively with antihypertensive agents and having cholesterol levels $6.5 \mathrm{mmol} / \mathrm{L}$ and below, meaning that they have a lower underlying risk of events. Furthermore, in our analysis we consider

Deleted: only patients who did not suffer an event during the blinded part of the trial, thus diluting the risk of events even further. Considering a cost-effectiveness perspective, the cost to gain a QALY from high adherence would be $£ 19,000$, which is below the threshold value of $£ 20,000$ - 30,000 per QALY employed by NICE. [25] High adherence would therefore be perceived as being of good value to society - even in this relative low risk group of patients. Compared to our previous analysis of amlodipine plus atorvastatin versus amlodipine alone, the cost per QALY is higher in this analysis. The reason may once again lie in the suggested carry-over effect, and the fact that patients with low- 
adherence still have some protection from their previous treatment. [20] By multiplying the number of days on drug with a daily cost, we also assumed a very low costs in the low adherence group. In practice, poor adherence would manifest itself not only as patients not filling their prescription, but also in patients filling their prescriptions and then not taking the drug, leading to wastage. If patients filled prescriptions for $25 \%$ of the days under study, the ICER would be reduced to $£ 15,000$ per QALY. If patients were to fill all prescriptions and take the medication to the extent reported here ( $7.3 \%$ of the time), persuading them to take the drug to the same extent as in the high adherence groups would lead to overall savings, albeit modest ones ( $£ 36$ per patient).

In our analysis, patients were still in the active follow up stage of ASCOT-BPLA. This adds strength to our analysis as data were collected in a controlled fashion, but it also adds some complications when extrapolating results. In the extrapolation presented here, the impact of non-adherence to the antihypertensive therapies was not considered. It could be argued that patients with a low adherence to statin also would have low adherence to other drugs. This needs to be taken into account when considering potential measures to improve adherence as the actions taken could have beneficial impact on blood pressure lowering as well.

s There are to date very few studies based on the observed effect of poor adherence to statin therapy. Our results indicate that there is a significant reduction of events in patients who are adherent, and that this translates into long-term benefits. An important area of future research would be to investigate what measures to improve adherence
Deleted: The economic effects of nonadherence to lipid lowering therapy have received very little attention in the literature so far. 
would be cost-effective. Based on the thresholds employed by NICE, there seems to be some room to take action. This will be particularly true when the price of the drug falls after the patent expires.

\begin{abstract}
Author contributions
PL was responsible for the concept/design of this substudy, data analysis and interpretation, and drafted the article. JE participated in data analysis and critical revision of the article. MB, TK, NP, BD, PS, HW and BJ provided input on the study concept and critically revised the manuscript. NP, BD, PS and HW formed the executive committee of the ASCOT trial.
\end{abstract}

\title{
Acknowledgements
}

The study was supported Pfizer Inc, New York, USA. Peter Lindgren and Jennifer Eriksson are employees of i3 Innovus, Stockholm, Sweden, who were paid consultants to Pfizer in connection with the development of the manuscript. Neil Poulter and Peter Sever are grateful for support from the NIHR Biomedical Research Centre funding scheme. We are grateful to Mattias Molin for analytical support. 


\section{Reference List}

[1] Sever PS, Dahlof B, Poulter NR, Wedel H, Beevers G, Caulfield M, et al. Prevention of coronary and stroke events with atorvastatin in hypertensive patients who have average or lower-than-average cholesterol concentrations, in the Anglo-Scandinavian Cardiac Outcomes Trial--Lipid Lowering Arm (ASCOTLLA): a multicentre randomised controlled trial. Lancet $2003 \mathrm{Apr}$ 5;361(9364):1149-58.

[2] Prevention of cardiovascular events and death with pravastatin in patients with coronary heart disease and a broad range of initial cholesterol levels. The LongTerm Intervention with Pravastatin in Ischaemic Disease (LIPID) Study Group. N Engl J Med 1998 Nov 5;339(19):1349-57.

[3] MRC/BHF Heart Protection Study of cholesterol lowering with simvastatin in 20,536 high-risk individuals: a randomised placebo-controlled trial. Lancet 2002 Jul 6;360(9326):7-22.

[4] Colhoun HM, Betteridge DJ, Durrington PN, Hitman GA, Neil HA, Livingstone SJ, et al. Primary prevention of cardiovascular disease with atorvastatin in type 2 diabetes in the Collaborative Atorvastatin Diabetes Study (CARDS): multicentre randomised placebo-controlled trial. Lancet 2004 Aug 21;364(9435):685-96.

[5] Downs JR, Clearfield M, Weis S, Whitney E, Shapiro DR, Beere PA, et al. Primary prevention of acute coronary events with lovastatin in men and women with average cholesterol levels: results of AFCAPS/TexCAPS. Air Force/Texas Coronary Atherosclerosis Prevention Study. JAMA 1998 May 27;279(20):161522.

[6] Randomised trial of cholesterol lowering in 4444 patients with coronary heart disease: the Scandinavian Simvastatin Survival Study (4S). Lancet 1994 Nov 19;344(8934):1383-9.

[7] Graham I, Atar D, Borch-Johnsen K, Boysen G, Burell G, Cifkova R, et al. European guidelines on cardiovascular disease prevention in clinical practice: executive summary. Eur Heart J 2007 Oct;28(19):2375-414.

[8] Caspard H, Chan AK, Walker AM. Compliance with a statin treatment in a usualcare setting: retrospective database analysis over 3 years after treatment initiation in health maintenance organization enrollees with dyslipidemia. Clin Ther 2005 Oct;27(10):1639-46.

[9] Chodick G, Shalev V, Gerber Y, Heymann AD, Silber H, Simah V, et al. Longterm persistence with statin treatment in a not-for-profit health maintenance organization: a population-based retrospective cohort study in Israel. Clin Ther 2008 Nov;30(11):2167-79. 
[10] Gislason GH, Rasmussen JN, Abildstrom SZ, Gadsboll N, Buch P, Friberg J, et al. Long-term compliance with beta-blockers, angiotensin-converting enzyme inhibitors, and statins after acute myocardial infarction. Eur Heart J 2006 May;27(10):1153-8.

[11] Kulkarni SP, Alexander KP, Lytle B, Heiss G, Peterson ED. Long-term adherence with cardiovascular drug regimens. Am Heart J 2006 Jan;151(1):185-91.

[12] Lachaine J, Rinfret S, Merikle EP, Tarride JE. Persistence and adherence to cholesterol lowering agents: evidence from Regie de l'Assurance Maladie du Quebec data. Am Heart J 2006 Jul;152(1):164-9.

[13] Vinker S, Shani M, Baevsky T, Elhayany A. Adherence with statins over 8 years in a usual care setting. Am J Manag Care 2008 Jun;14(6):388-92.

[14] Rasmussen JN, Chong A, Alter DA. Relationship between adherence to evidencebased pharmacotherapy and long-term mortality after acute myocardial infarction. JAMA 2007 Jan 10;297(2):177-86.

[15] Ho PM, Magid DJ, Masoudi FA, McClure DL, Rumsfeld JS. Adherence to cardioprotective medications and mortality among patients with diabetes and ischemic heart disease. BMC Cardiovasc Disord 2006 Dec 15;6:48.:48.

[16] Bouchard MH, Dragomir A, Blais L, Berard A, Pilon D, Perreault S. Impact of adherence to statins on coronary artery disease in primary prevention. Br J Clin Pharmacol 2007 Jun;63(6):698-708.

[17] Perreault S, Dragomir A, Blais L, Berard A, Lalonde L, White M. Impact of adherence to statins on chronic heart failure in primary prevention. Br J Clin Pharmacol 2008 Nov;66(5):706-16.

[18] Sokol MC, McGuigan KA, Verbrugge RR, Epstein RS. Impact of medication adherence on hospitalization risk and healthcare cost. Med Care 2005 Jun;43(6):521-30.

[19] Dahlof B, Sever PS, Poulter NR, Wedel H, Beevers DG, Caulfield M, et al. Prevention of cardiovascular events with an antihypertensive regimen of amlodipine adding perindopril as required versus atenolol adding bendroflumethiazide as required, in the Anglo-Scandinavian Cardiac Outcomes Trial-Blood Pressure Lowering Arm (ASCOT-BPLA): a multicentre randomised controlled trial. Lancet 2005 Sep 10;366(9489):895-906.

[20] Sever PS, Poulter NR, Dahlof B, Wedel H, Beevers G, Caulfield M, et al. The Anglo-Scandinavian Cardiac Outcomes Trial lipid lowering arm: extended observations 2 years after trial closure. Eur Heart J 2008 Feb;29(4):499-508.

[21] Sever PS, Dahlof B, Poulter NR, Wedel H, Beevers G, Caulfield M, et al. Rationale, design, methods and baseline demography of participants of the Anglo- 
Scandinavian Cardiac Outcomes Trial. ASCOT investigators. J Hypertens 2001 Jun;19(6):1139-47.

[22] Lindgren P, Buxton M, Kahan T, Poulter NR, Dahlof B, Sever PS, et al. The lifetime cost effectiveness of amlodipine-based therapy plus atorvastatin compared with atenolol plus atorvastatin, amlodipine-based therapy alone and atenolol-based therapy alone: results from ASCOT. Pharmacoeconomics 2009;27(3):221-30.

[23] Dolan P, Roberts J. Modelling valuations for Eq-5d health states: an alternative model using differences in valuations. Med Care 2002 May;40(5):442-6.

[24] Lindgren P, Buxton M, Kahan T, Poulter NR, Dahlof B, Sever PS, et al. Economic evaluation of ASCOT-BPLA: antihypertensive treatment with an amlodipine-based regimen is cost effective compared with an atenolol-based regimen. Heart $2008 \mathrm{Feb}$;94(2):e4.

[25] 'National Institute of Clinical Excellence'. Guide to the methods of technology appraisal. 2007.

[26] Compliance and adverse event withdrawal: their impact on the West of Scotland Coronary Prevention Study. Eur Heart J 1997 Nov;18(11):1718-24.

[27] Simpson SH, Eurich DT, Majumdar SR, Padwal RS, Tsuyuki RT, Varney J, et al. A meta-analysis of the association between adherence to drug therapy and mortality. BMJ 2006 Jul 1;333(7557):15.

[28] Ho PM, Magid DJ, Shetterly SM, Olson KL, Maddox TM, Peterson PN, et al. Medication nonadherence is associated with a broad range of adverse outcomes in patients with coronary artery disease. Am Heart J 2008 Apr;155(4):772-9. 
Table 1: Baseline characteristics for Atorvastatin patients with low $(<50 \%)$ or high $(>\mathbf{8 0} \%)$ adherence to atorvastatin during ASCOT-LLA extended follow-up

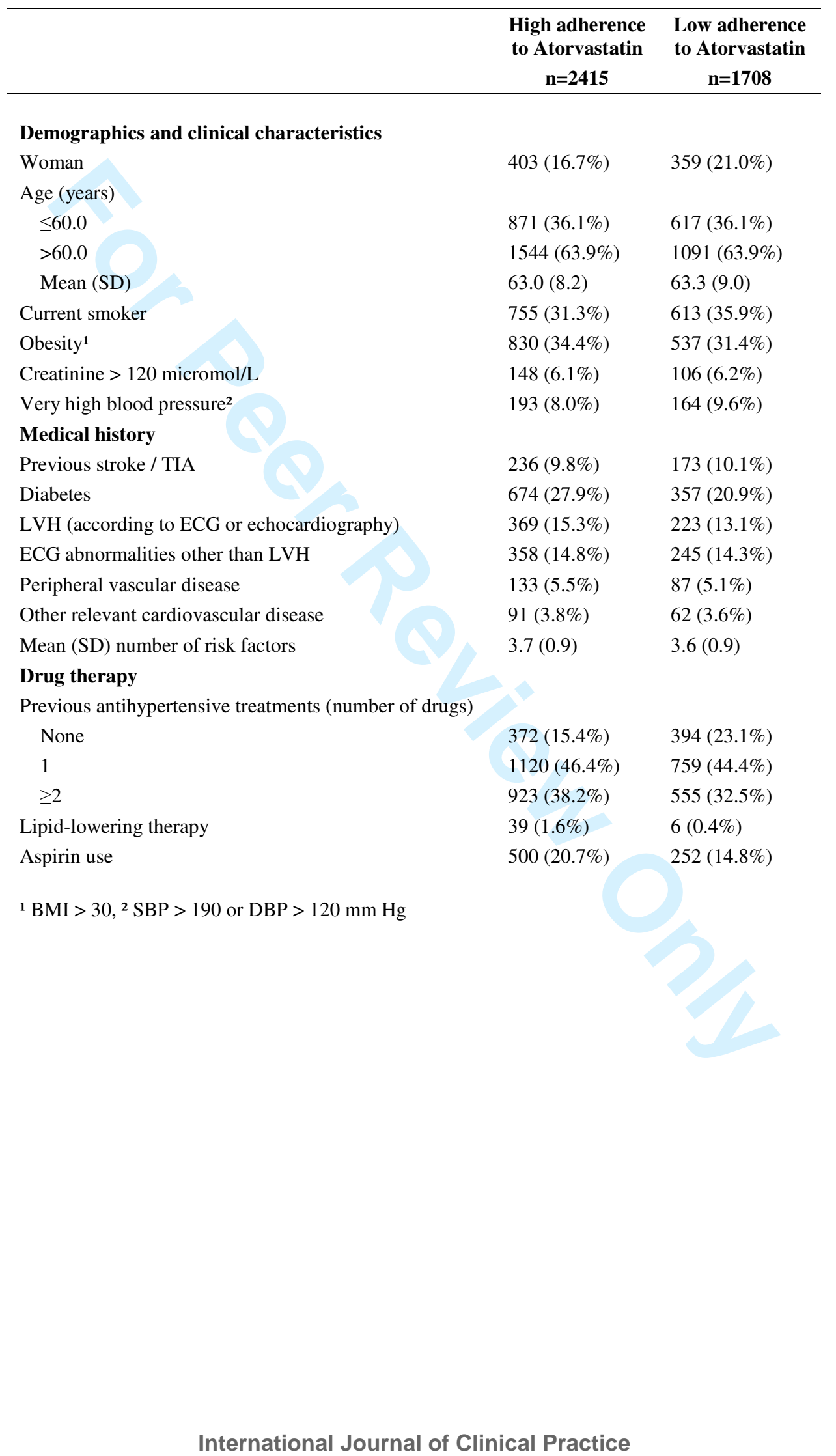


Table 2: Hazard ratios (95\% confidence interval) on the risk of cardiovascular events and procedures during the open-label follow-up of ASCOT-LLA

\begin{tabular}{lcc}
\hline & $\begin{array}{c}\text { Cox proportional hazards } \\
\text { model }\end{array}$ & Poisson model \\
\hline Cardiovascular risk (in \%) & $1.06(1.03-1.09)^{* *}$ & $1.06(1.03-1.09)^{* *}$ \\
Accumulated adherence 50\%-80\% & $0.73(0.46-1.14)$ & $0.71(0.46-1.12)$ \\
Accumulated adherence $>80 \%$ & $0.75(0.57-0.98)^{*}$ & $0.73(0.56-0.96)^{*}$ \\
Current age & $1.03(1.02-1.05)^{* *}$ & $1.03(1.02-1.05)^{* *}$ \\
Time since entry in follow-up & na & $0.91(0.75-1.10)$ \\
$* \mathrm{p}<0.05 ; * * \mathrm{p}<0.001$ & &
\end{tabular}

Table 3: Predicted per-patient long-term costs ( $(\mathfrak{)})$ and health outcomes

\begin{tabular}{lccc}
\hline & High adherence & Low adherence & Difference \\
\hline Cost of lipid lowering & 427 & 33 & \\
Other health care costs & 1,252 & 1,290 & 353 \\
Total cost & 1,689 & 1,323 & -38 \\
& & & 366 \\
Predicted life years & 10.83 & 10.81 & 0.02 \\
Predicted QALY & 8.13 & 8.11 & 0.02
\end{tabular}


Figure 1: Cost-effectiveness scatter plot of the probabilistic sensitivity analysis comparing the net difference in costs and effects between the high adherence and low-adherence groups.

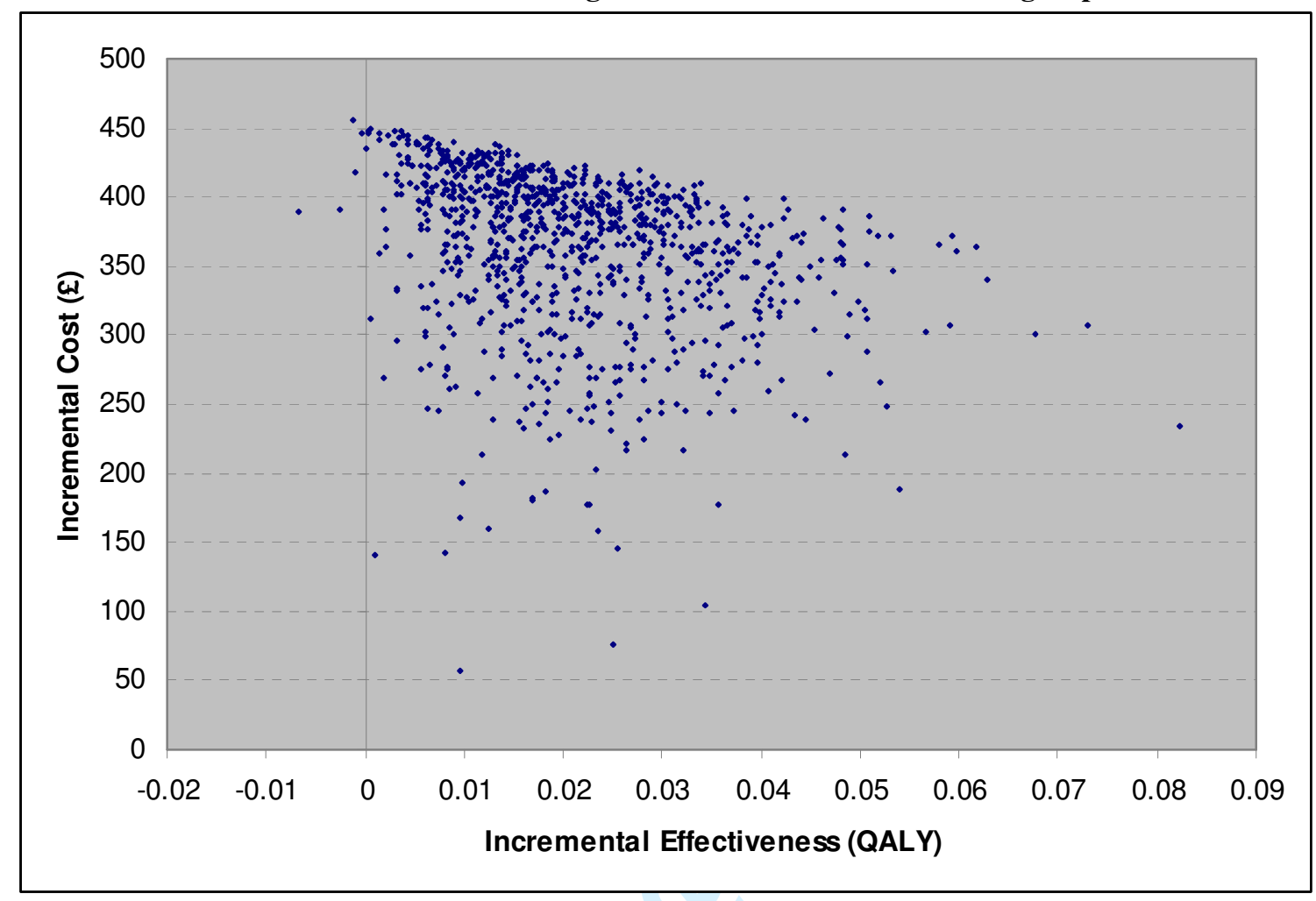

\section{$\underline{\text { Legend }}$}

Each dot represent the net cost and QALY from one simulation where all model inputs are drawn from their underlying distribution, thus giving an estimate of the joint parameter uncertainty in the model. 
Figure 2: Tornado diagram with results from sensitivity analyses on key model inputs.

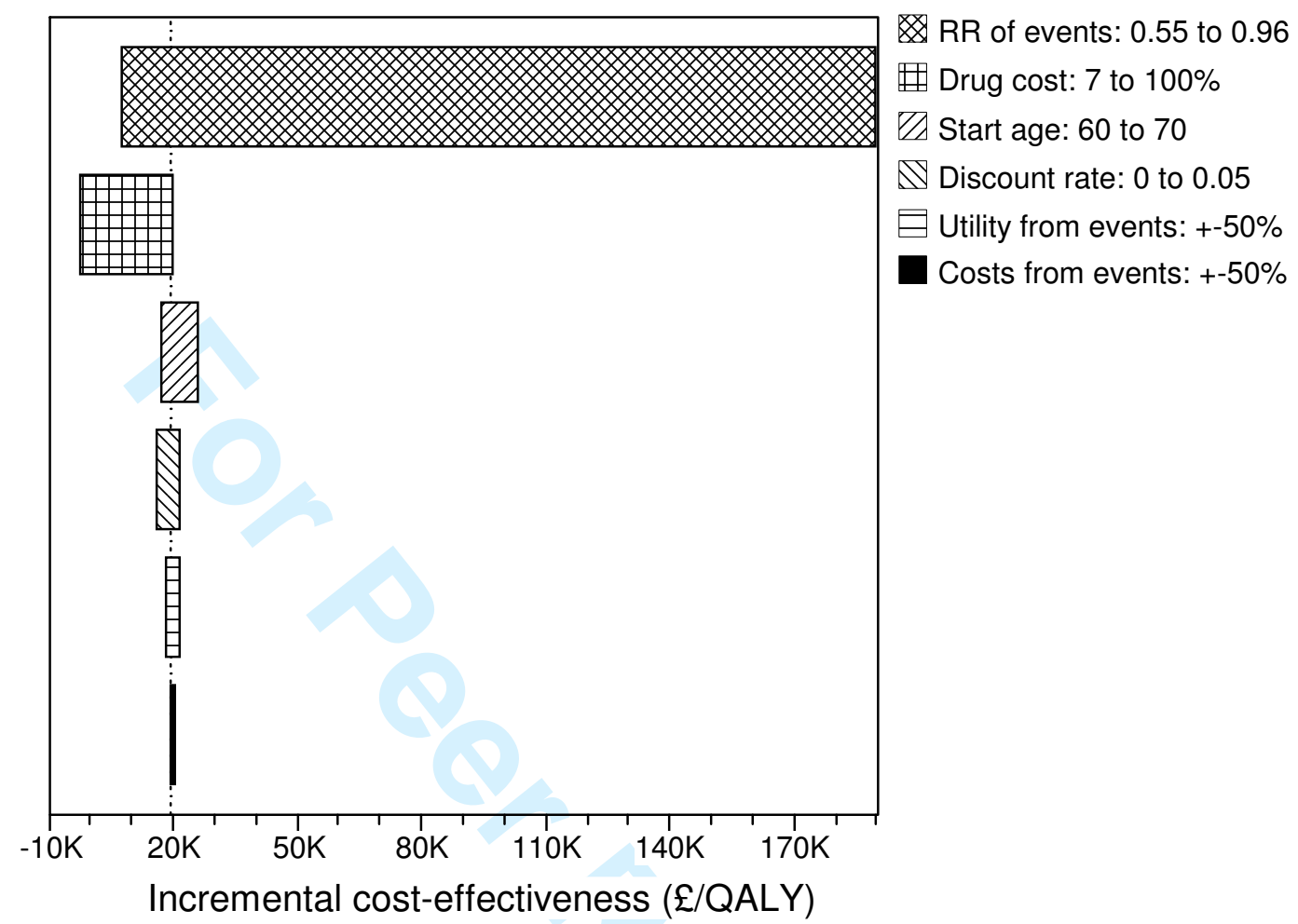

\section{Legend}

$R R$ of events: The relative risk of events in the high adherence group. Drug cost: The proportion of days patients in the low-adherence group accrue drug costs. Start age: The starting age of the cohort. Discount rate: The yearly discount rate applied to costs and effects. Utility from events: A modification to the utility reduction caused by events. Costs from events: A modification to the cost of events. 